\title{
Phenomenology of Rhythm: The Role of Rhythm in Written Language
}

\author{
Casper Feilberg! (D) \& John Maul ${ }^{2}$ \\ ${ }^{1}$ Aalborg University, Department of Communication and Psychology, Teglgårds plads 1, 9000 \\ Aalborg, Denmark \\ ${ }^{2}$ Independent researcher, Hornbakvej 82, 9270 Klarup, Denmark
}

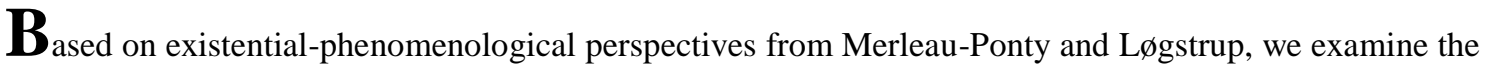
significance of rhythm for written language skills. Rhythm is both omnipresent and a difficult phenomenon to explore. Methodologically, the article presents phenomenological descriptions and exemplifications, not least a case study of a secondary school student with written language difficulties. Our intention is to illuminate connections between rhythmic perspectives in movement, speech, working memory and language as prerequisites for the acquisition of written language skills. We conclude that rhythm is an essential aspect of our bodily being, and based on the work of Merleau-Ponty, we are able to bring to light relationships between body, rhythm, and written language skills in ways that would not be possible from a natural scientific point of view. Inspired by Merleau-Ponty's analytical approach and the hermeneutic phenomenology of Ricoeur, we will combine an understanding perspective with both human scientific and natural scientific explanations, into a holistic interpretation. The article thus draws empirically on qualitative descriptions of rhythmic phenomena, and theoretically on perspectives from philosophy of language, developmental psychology and neuropsychology, but they are all interpreted in the light of existential-phenomenological ontology.
\end{abstract}

Key Words: Researching Rhythms, Existential Phenomenology, Qualitative Case Study, Writing, Reading, Dyslexia

\section{Introduction}

Rhythm comes from the Greek 'rhythmos' meaning 'wave' or 'a regular recurring motion' with strong and weak elements, as in the pronunciation of the word phenomenon. Pronounced without stress and accent, all speech would be a monotonous and undifferentiated mass. Rhythm also plays a 
significant role in our ability to express ourselves in writing, which is the focal point of this article. We will examine the significance of rhythm for written language skills, but we will do so through a holistic interpretation of the many activities that are involved in being able to express ourselves in writing - such as the acquisition of language, being able to read, being able to read aloud and convey a meaning, and finally being able to write and express oneself as a whole. With respect to all of these activities, rhythm constitutes both an omnipresent and an implicit phenomenon, which nevertheless holds the key to understanding more about written language skills in general, and written language difficulties (dyslexia) in particular. Out of the existential phenomenologists, Maurice Merleau-Ponty and Knud E. Løgstrup in particular, have dealt with language and music including rhythm. We will show that particularly existential phenomenology is an obvious basis for analyzing and understanding the significance of rhythm for written language skills (Compton, 1997; Feilberg, 2012, 2014, 2019).

There is something mysterious or rather magical about our ability to communicate through language and written language. As part of his analysis of the patient Schneider, Merleau-Ponty (2012) makes use of the metaphor of a melody to describe the magic of an everyday event such as retelling a story. Due to a brain damage Schneider is unable to retell a story: "And indeed, if the patient is told a story, rather than grasping it as a melodic whole with its strong and weak beats and with its characteristic rhythm or flow, he only retains it as a series of facts that must be recorded one by one" (Merleau-Ponty, 2012, p. 134). According to Merleau-Ponty, we are (unlike Schneider) able to understand a story because we grasp it as a 'melodic whole', with a 'characteristic rhythm' and strong and weak beats, through which we "accentuate" some parts and others less so, and thus the story is meaningful as a 'lived' 'human event' (ibid.). All this happens before any explicit analysis and as part of the normal subject's power to live the event by identifying herself with the situation and thus give meaning to it (ibid., pp. 134-135). All this happens at a pre-reflective and bodily level of our being, which we cannot fully explain in a natural scientific way. The same goes for the phrases we formulate in normal fluent speech. They are, according to Merleau-Ponty, "organized all by itself' (Merleau-Ponty, 1967, p. 87). But, adds Merleau-Ponty, "The first words must already have the kind of rhythm and accent which is appropriate to the end of the sentence, which is nevertheless not yet determined, except as the last notes of a melody are performed in its global structure.” (1967, p. 87). Expressed in other words, the beginning of the sentence is rhythmical and accent-wise organized in relation to the whole. In the normal person, it happens all by itself.

In relation to music, Merleau-Ponty observes the following: "The same notes in two different melodies are not recognized as such. Inversely, the same melody can be played two times without the 
two versions having a single common element if it has been transposed" (1967, p. 87). And MerleauPonty points out that the same can be said of language. According to Merleau-Ponty, the note of the music or the sound of speech emerges only as a figure and an experience, by virtue of a background or a context that together creates a gestalt. A gestalt or a holistic experience that represents more than the individual parts. In the background, the body and rhythm play a crucial role for the experience or the expression that is perceived or created. This background is ultimately the lifeworld understood as a common social and cultural background of meaning (Barbaras, 2005, pp. 208, 227-228). In other words, there is a play between what we directly live and experience, and the background from which the experienced emerges (ibid.).

An understanding of this interaction between body and world, and between figure and background, is a central theme in existential phenomenology, and it suggests that a phenomenological approach is relevant to examine and to understand the importance of rhythm for oral and written communication. But not only phenomenology. The question of language acquisition, reading and writing is so complex that a philosophical approach as well as an interdisciplinary approach is necessary to gain a glimpse of the fundamental significance that rhythm has on these activities. Let us take a closer look at the essence of language from a linguistic and a phenomenological point of view, and return to our argument for the human scientific, qualitative and existentialphenomenological approach in this article to rhythm and language.

\section{The body and rhythm in relation to language}

To Merleau-Ponty (2012), the body forms a magical connection with the world at a pre-reflective level. Rhythm appears as an interplay between the silent bodily knowledge and the reflective thought, which is also reflected in the fact that you only know what you mean when you have heard what you say (ibid., p. 425). And when we listen to the speech of others, the fact is that we sense the language as little as the ears we hear with. The language 'will be overlooked' according to Løgstrup (1976, p. 174), it is transparent and belongs to our pre-reflective being and bodily habits. The fish does not care about the water in which it swims any more than we care about the language we are surrounded by. We do not hear speech, we hear meaning - we are as Merleau-Ponty has expressed it "condemned to sense" (2012, p. lxxxiv). We cannot choose to hear a familiar language as noise. Hence the cliché: 'I could not help overhearing what you said'. If you have to reproduce what someone else has said, it will extremely rarely be a faithful copy, but you reproduce the contents in other words. And likewise with rhythm. 
We cannot analyze rhythms in the same act as we live them, according to Lefebvre (2013, p. 95). Nor can the rhythm of language be accounted for in linguistics, neither objectively nor scientifically. Linguists such as Hansen and Lund (1983) had to give up defining the rhythm of sentences and instead just state: "Native Danes generally agree on where to put stress and what is accented" (Hansen and Lund, 1983, our transl.). But according to the philosopher of language Grønbech it is possible to understand the role of rhythm in speech: "In words I can communicate my thoughts to the outside world - partly though; in the melody I announce the deep play of thought" (1943 p. 66, our trans1.). The rhythm of speech in the form of prosody and intonation is also referred to as suprasegmental, ie. that these are elements which are underlying the noticeable speech sounds, by which they evade a linguistic and phonetic analysis. For instance, it can be exemplified by the fact that in modern hearing aids the sounds from the bass area are amplified, which otherwise extend below the normal speech area and therefore have no effect on the perception and discrimination of the speech sounds. But one gets the chance to catch the rhythmic and prosodic elements of the language, and it has proven to be an important aid for perceiving and understanding linguistic meaning and significance.

This is why in the effort to obtain scientific explanations about the cause of written language difficulties based on linguistics (eg. Elbro 1990), one is easily led to assumptions that overlook perspectives of philosophy of language as well as qualitative perspectives of being. The result will be an absorption in one's own partial understanding, where, for example, the linguistic awareness is made the focal point of theory formation, causal explanations, and intervention, as it is evident from the linguistic reading theory of Elbro (1990). Our existential-phenomenological and qualitative perspectives will challenge Elbro's linguistic reading theory and other linguistic theories.

In linguistics, one deals with the objective language which can be dissected and measured. In the philosophy of language, one deals with the lived language as it is practiced. Unlike such a technical knowledge-guiding interest in prediction and control of objectified processes, a practicalunderstanding knowledge-guiding interest will lead the researcher to develop descriptions and theoretical concepts that can contribute to a greater understanding of the matter (Habermas, 1978; Gadamer, 2004).

The work of Merleau-Ponty $(2012,1968)$ is a good example of this practical-understanding knowledge-guiding interest. In his works, he was preoccupied with understanding our immediate experience in a way that did not lead to an intellectualization of our being-in-the-world or to a reduction of it from an objectivist conception of science. To Merleau-Ponty: 
"Literature, music, the passions, but also the experience of the visible world are - no less than is the science of Lavoisier and Ampère - the exploration of an invisible and the disclosure of a universe of ideas. The difference is simply that this invisible, these ideas, unlike those of that [natural] science, cannot be detached from the sensible appearances and be erected into a second positivity" (Merleau-Ponty, 1968, p. 149).

According to existential phenomenology, when we inquire into the sense of rhythm with respect to writing or other human phenomena from a practical-understanding knowledge-guiding interest, we cannot do so without taking the experiential dimension into account. This is different from the explorations of physical objects made by natural science such as physics and chemistry, which is able to do just that: put the ideas of things into a second positivity with concepts such as ampere, voltage etc.

Inquiry into lived human phenomena demands a fundamentally different approach than a natural scientific knowledge-guiding interest. Because, according to Merleau-Ponty, "We do not possess the musical or sensible ideas, precisely because they are negativity or absence circumscribed; they possess us" (1968, p. 151). We are only given the opportunity to explore and understand the 'ideas' or the phenomena, because they are not separate from ourselves as an object on the laboratory table, but on the contrary are part of ourselves and our lifeworld as corporeal and perceptive beings (ibid., p. 150). Merleau-Ponty puts it this way: the phenomenological "...philosopher is always implicated in the problems he poses" (1968, p. 90). The phenomenological ontology of Merleau-Ponty is an indirect ontology of fleshly being (1968, p. 88, 179), meaning it tries to describe "the immediate perception of sense and significance that does not really appear directly" (Feilberg, Norlyk \& Keller, 2018, p. 218). In this article, we take on the same aim with respect to rhythm and written language skills.

In describing such an indirect ontology, Merleau-Ponty is well aware of the impossibility of fully expressing this ontology through language as a 'second positivity'. Even our qualitative descriptions of an experience are not quite close to our perception and immediate experience: "The explicitation does not give us the idea itself; it is but a second version of it, a more manageable derivative" (1968, p. 150). Descriptions remain a derivative version of the lived phenomenon.

The phenomenon of human science research is made more understandable through analysis and language, but never fully grasped, unless the reader at the same time sense what is discussed in the light of her own corporeal being and lived experience. Therefore, Merleau-Ponty has chosen the poetic and literary style in his existential phenomenology, as a break off from and a development of 
Husserlian phenomenology (Olesen, 1993; Merleau-Ponty, 2012, p. 1xxxiv). He makes use of literature, metaphors, case examples and other examples from everyday life, in order to describe and bring alive the phenomena that he analyzes. If, as a writer, one succeeds in bringing life and movement to the reader through the language, the phenomena that are scientifically described and investigated can at the same time appear in the reader by virtue of his bodily being as well as the common social and cultural lifeworld; and here rhythm has a special significance for bringing phenomena to 'life' in reading, speaking and writing, three of the central topics of the article.

In this article, we will go beyond phenomenological descriptions, and in line with the spirit of Merleau-Ponty's work (2012) combine descriptions of immediate experiences and qualitative observations with natural scientific and human scientific perspectives. The descriptions and the explanatory perspectives culminate altogether in what Ricoeur in Explanation and Understanding (1991) has called an interpretation. Merleau-Ponty (2012) is also known for incorporating perspectives of developmental psychology and gestalt-psychology in his phenomenological work, by which we are also inspired. In this article, we draw on knowledge from neuropsychology, linguistics, phonetics, developmental psychology, philosophy of language, and combine it with a qualitative interpretation of a case study (Maul, 2000; Feilberg \& Maul, 2019).

The rest of the article is organized as follows: In section A) we present preliminary perspectives on language, reading and writing in the normal subject from existential phenomenology, philosophy of language, developmental psychology and music theory. Though in order to better understand the invisible and implicit character of rhythm and writing, we introduce a qualitative case study of a young man with dyslexia called Brian. In section B) we present the methodological reflections and the qualitative case study that make possible a more developed phenomenological analysis of rhythm in writing. In the case of Brian, we are able to bring to light relationships between the way of walking, writing by hand, speaking, remembering rhymes, spelling, reading and expressing oneself in writing, all of which have aspects of rhythm in them. In section $C$ ) we will discuss our findings on rhythm and its consequences to our understanding of written language skills, dyslexia and qualitative inquiry in general.

There are a number of other contributions to phenomenological analysis of rhythm, such as Grants' Some Suggestions for a Phenomenology of Rhythm (2010), which is specifically about music. Wiskus (2013) has also analyzed rhythm in music as a way of shedding new light on our bodily involvement 
in the world, and the importance of art for philosophical reflection. But none of these examines the significance of rhythm on written language skills.

\section{A) Forming the basis of understanding the mystery of language}

\section{To express oneself in writing through the body}

Merleau-Ponty (2012, pp. 145-146) describes the enigmatic interplay between body and mind at play when typing at a pre-reflective level. A person can express his thoughts via the keyboard without having any conscious knowledge of where on the keys the individual fingers are located. If you have learned to touch type with all ten fingers you no longer know where on the keyboard the individual fingers are, all the while you are formulating meaningful sentences on the computer screen. To Merleau-Ponty, "It is a question of a knowledge in our hands, which is only given through a bodily effort and cannot be translated by an objective designation" (2012, p. 145). And he links this phenomenon directly to the organist's musical manifestations on the keyboard in the church, and states that an experienced organist can play on different keyboards in several churches (2012, p. 146). But as with the keys on the keyboard, it is not the position of the individual keys in relation to the fingers on the keyboard that is decisive, but rather the body's rhythmic movements that give meaning and accent to language and music. Orienting oneself on the keyboard does not presuppose mental images of its geometric coordinates, but rather that their spaciousness is incarnated and is already in the body, arms and fingers as a habit.

When, by contrast, you write by hand with a pencil, other additional dimensions are brought into play. First, we can talk about the 'movement paths' of the letters, which in childhood are picked up as learned motor clichés, which are always performed for each individual letter in a continuous course of movement with the same beginning and end each time. It is often referred to as automation of alphabetic writing and is the result of many erratic attempts in early childhood towards a confident performance; which, rather than automated, is rhythmized, i.e. embedded in obvious movement patterns similar to the same letter each time. Just like Chinese and Japanese graphic characters, which are not, as many believe, drawn as spatial figures, but rather as a result of fluid movement patterns in implied and rhythmized, habitual sequences of movement. Such movements are often described as automated movements, stemming from the Greek autómatos for self-moving or self-willed, but rhythmizing is a better term. And that is because automating in a modern sense refers to automaton and machine, while rhythmizing points to a bodily expression of motor learned and self-evident 
habits. Writing thus becomes a progressive and rhythmized movement that almost proceeds by itself prior to the conscious thought.

This leads directly to the next stage of a normal development of handwriting, which is the connection of the writing in fluent handwriting. Common to all connected forms of handwriting is that they are based on 'kinetic movement melodies' as a prerequisite for the handwriting to flow completely freely and the writer to be preoccupied with the content in the same way as on the keyboard. Merleau-Ponty refers to typewriting as a 'modulation of motricity' and a 'modulation of the manual space' (Merleau-Ponty, 2012, p. 145). Modulation comes from Latin: modulātiōn, ie. adjust the pitch, tone, or volume of your voice, in this context modulation or rhythmization of motricity. These processes occur pre-reflectively when they are acquired. One way to learn more about the importance of motricity for written language skills is by examining dyslexic students' difficulties with rhythmizations. This is done in section B.

\section{Rhythm as a fundamental phenomenon in speech, language and written language skills}

The rhythmic perspectives will now be expanded from typing and handwriting to speech, language and written language skills. We begin with a perspective of developmental psychology, as rhythm is at play in human developmental psychology from before birth. The Scottish child psychologist Threvarten and the Norwegian music researcher Bjørkvold have presented important knowledge in this area. According to Bjørkvold (1992), already at an early embryonic stage, the future human being is affected by 'the music of the earth'. Gravity is the first sensory perception we receive and that forever connects us to our position in the universe as the core point of all sorts of other sensory perceptions. And immediately thereafter, the sense of hearing follows and the fetus is stimulated early with the mother's heartbeat and the deepest notes from the surroundings, just like when you hear music or voices as a dull sound through walls corresponding to the mother's body. It is predominantly a rhythmic influence with deep notes containing the melody of speech (ibid.).

The development of language thus begins before birth. It begins with tone, tempo and dynamics, and for the fetus it is the music in the mother's voice that matters, not the semantic meaning of the words. Experiments have suggested that newly born babies can recognize fragments of nursery rhymes that their pregnant mothers read aloud to them during pregnancy (ibid.). Once the baby is born, the rhythmic interaction between mother and baby continues in the form of a synchronization of motricity, facial expressions and sounds. The newborn's motricity is implemented and 
synchronized with the adult's organized language acts. In Bjørkvold's (1992) view the mother tongue is imprinted into the infant's body as an interplay of sound, rhythm and movement.

Trevarthen $(1987,1988,1999,2010)$ imagines that the mother, like a conductor, strikes with the baton and creates a mutual understanding between herself and the child regarding a basic pulse. These first conversations create musical forms of participation, where the common tempo tends towards a slow andante or an adagio. The infant's early vocalizations have metric and harmonic features that can be compared with both speech and with a musical performance. This provides a prosodic framework for the development of conversations. Not only in the interaction between infant and adult, but also in the adult's conversation, has synchronicity been demonstrated between the speaker's voice and the listener's body movements. And it shapes our spoken language and reading skills in ways of which we are not aware, but that philosophy of language can shed light on. German philosopher Julius Stenzel's work Philosophie der Sprache (1934) is particularly relevant here. Løgstrup sums up Stenzel's insight as follows:

"Thanks to the tone and the timbre of the words, we are set, just as surely as imperceptibly, in a certain direction, and not only by the spoken, but also by the written word. The acoustic figure that the sentence, not least as a rhythmic whole, gets from the intention of meaning, is important. He who reads without overseeing the whole does not understand what he is reading and he is not understood. To the meaning corresponds a rhythmic clause of the sentence as a sound figure, and that is the prerequisite for speech and comprehension. The raising and lowering of the voice, pauses, are means of clarifying what is meant. It is a misconception that the language is composed of already definitively finished parts. Rather, the real life of language is fulfilling itself much more in the influence of the whole on the parts, the sentence on the word, the word on the syllable, the syllable on the sound." (Løgstrup, 1976 p. 12, our transl.)

According to Stenzel rhythm plays a significant role in fluent reading anticipating and adjusting the course of the process so that the prosody - the direct connection to understanding - supports the listener through difficult paragraphs.

This support via the prosody occurs immediately and by itself, so that one often notices its necessity only when it is absent, as we saw in the example of Schneider (Merleau-Ponty, 2012). Let us bring another example. Some people who suffer from autism can read technically perfectly and 
seemingly completely unobtrusively, but they reveal themselves in their reading with their deviant accents and rhythm; and it turns out that they do not have a full understanding of the content they are reading. It is equivalent to being able to play technically perfectly on a musical instrument, but only those who have the intention of expressing a feeling or a meaning with the music are seriously recognized. The existential phenomenologist Knud E. Løgstrup elaborates on the same relationship as regards reading:

"If a person reads aloud, a speaker on the radio for example, he may lecture very clearly, distinctly and correctly, but if he thinks of other things or does not understand what he is reading, you notice it immediately, and you notice it by having to constantly make an effort to understand what he is saying, although the content is quite simple and straightforward. Understanding the spoken does not go as otherwise by itself. The words are only syntactically linked, and it is not enough, they must be connected in meaning, and they are not, because the tone takes care of that, and it is missing" (Løgstrup, 1976, p. 11, our transl.).

Løgstrup emphasizes here once again the accent and thus the rhythm as the main phenomenon in both reading and understanding what is read.

The Danish musician Peter Bastian continues this line of thinking under the heading 'Resonance' in his main work Into the Music (1987, p. 47): "We are hit by sound waves, and then we begin to feel. The energy in the body flows differently and is distributed differently". Peter Bastian sees a relatedness between the 'reading' of a piece of music and the reading of a text.

"The work process is a constant interaction between the linear analysis and the holistic design. We can perceive the music image as a text consisting of 'words', 'sentences' and 'paragraphs'. We say that the melody articulates in words, sentences and paragraphs, but in contrast to the written language, where there is a pause between the individual words, syntax, comma and full stop, the note image looks like this: 'thereisnospacebetweenthewords"' (Bastian 1987, p. 104, our transl.).

Admittedly, in the music image the composer can indicate certain signs of help, but it is the musician who, by his own pausing and accent, has to perform the music. This requires prior practice and experience, and sometimes during rehearsal you can hear the music performed as follows: 'ther eisn ospa cebetw eent hewo rds' (ibid.). And then it might sound like a person who has difficulty reading 
aloud with random accent and pausing, where it should have sounded like this: 'there is no space between the words' (ibid.). Phenomenologically, the same thing is true for the reader of a text who, according to Merleau-Ponty, is met by a meaningful organization of words and stress that organizes itself before the person's eyes as a gestalt or a whole (2012, p. 147; 1967, 87). It happens naturally and implicitly for most of us. Therefore, the significance of rhythm emerges more clearly in people who do not have these skills as natural habits, such as in people with dyslexia.

\section{B) Deepening the understanding of written language through a case study of dyslexia}

\section{Presentation of the qualitative assessment}

Inspired by Merleau-Ponty's use of cases in Phenomenology of Perception (2012), we take a case study of a secondary school student with written language difficulties as our starting point. This case makes it possible to further investigate the significance of rhythm as a prerequisite for written language skills. The case is based on qualitative observations, descriptions, anamnesis and an assessment report. The assessment of dyslexia is based on a qualitative test material developed by Maul (2000). This test material is inspired by A.R. Luria's qualitative neuropsychological investigation structure (Christensen, 1975, 1999). Maul's qualitative observations and assessments of dyslexic students led him to write a PhD dissertation that identified a rhythmic-sequential theme in these students (Maul 1995 and 2000). The rhythmic alludes to an accent in a linear pattern, partly with relations to movement patterns, partly with relations to intonation and prosody. The sequential alludes to a series of consecutive accents in motor movement sequences and the linguistic syntax. By theme is meant a set of elements of characteristic features that have a way of appearing again and again, e.g. in music and here in dyslexia as a fundamental set of characteristics in a person (ibid.).

Luria's neuropsychological investigation procedures were developed for the evaluation of brain injuries and higher functions (Christensen, 1975, 1999). The Danish version of the investigation procedures has since been developed into several different test materials with different purposes, including the assessment of dyslexia (Maul 2000a). Thus, it is not a standardized test that produces objective, measurable and operationalizable data. On the other hand, it is a qualitative assessment which develops understanding by virtue of the prehistory, the test material, the observations, the situation and the ability to communicate the findings in an assessable way (Maul, 1995, 2000, 2000a and 2019). The evaluation situation itself is not standardized either, as it takes place as a 'dialogue' 
between the assessor and the student in a way where the test material is harmonized with the student's answers in a fluid interaction. Bringing an exploratory and qualitative test material into play presents a unique opportunity to experience the diversity of signs of dyslexia.

In the assessment situation, observation, interaction and communication are all important elements for the development of a holistic interpretation. The intention of the assessment has been to observe, describe and interpret signs of dyslexia in order to identify relevant special educational recommendations.

Briefly, the test material consists of four key procedures to assess prerequisites for written language skills: Rhythmic-motor skills, perceptual skills: auditory, visual, spatial and tactile kinesthetic, impressive language skills and expressive language skills. All of these skills play an important role in reading and spelling.

Via the test material, the student's dyslexic signs are thematized. The term 'theme' (Maul, 1995 , pp. $7-8,168$ ) refers to something that has a way of appearing in exactly the same way as the theme of a piece of music. It is recognizable when it appears again and again, but as the theme of a piece of music can be performed with different instruments and still be audibly recognizable, the themes of dyslexia are not played with exactly the same combinations of difficulties every time. It varies according to the fact that each person is both unique and typical at the same time, and has his or her own personal prerequisites and difficulties that must be taken into account.

The case selected for this text has been chosen from among 100 other cases in John Maul's $\mathrm{PhD}$ thesis (1995) on Studies in a Rhythmic Sequential Theme in Dyslexia. With this case in particular and the other 99 cases as nuances and variants, the idea arose of a rhythmic-sequential theme in dyslexia. It will be described in the following using the case of Brian. Through the case, we will try to highlight rhythmic-motor contexts from the way of walking, speaking, remembering meaningless rhymes, inflectional endings, spelling patterns and reading aloud, in other words a special and pervasive theme in written language difficulties. Furthermore, these contexts can shed light on the importance of rhythm for written language skills in general.

\section{Presentation of Brian - an unusual mathematician}

Brian went to a special needs pre-school at a special education institution before starting school. The medical record from that period mentions expressive dysphasia in the form of syntactic difficulties and difficulties articulating fluency correctly in age-appropriate sentences. But he also showed good language comprehension and normal giftedness. Brian's school career was hampered by reading 
difficulties over a long period of time and spelling difficulties throughout. In return, he did so well in science subjects such as mathematics, physics and chemistry that he could be admitted to a mathematical upper secondary school. During his first year, his Danish teacher realizes that he has some unusual difficulties in spelling and writing, while his French teacher notices unusually persistent difficulties in acquiring and remembering French phrases. Hard-pressed by the academic requirements, he makes excuses by saying that he already as a child went to a special needs preschool at a special education institution, and they refer him to it again, and John Maul is given the task of assessing his written language difficulties based on the anamnestic information from the medical record at the institution.

\section{Observations from the qualitative assessment of Brian}

Brian seemed clearly nervous when he came the first day of assessment. He went up the stairs arrhythmically and staccato-like. During the following hour and a half, he remained seated at a table opposite John Maul. Brian was presented with a series of activities aimed at identifying the crucial prerequisites for reading and spelling. During the assessment procedure, the following three characteristics were observed.

1) Drawing test: The first characteristic was seen when Brian was to trace sequential patterns. It went fairly well with the first ones, though he drew them big and rough. But as he traced the third and final pattern, it was as if he lost control and the pattern disintegrated for him. It was clear that he was easily exhausted and could not fluently and rhythmically trace simple sequential patterns.

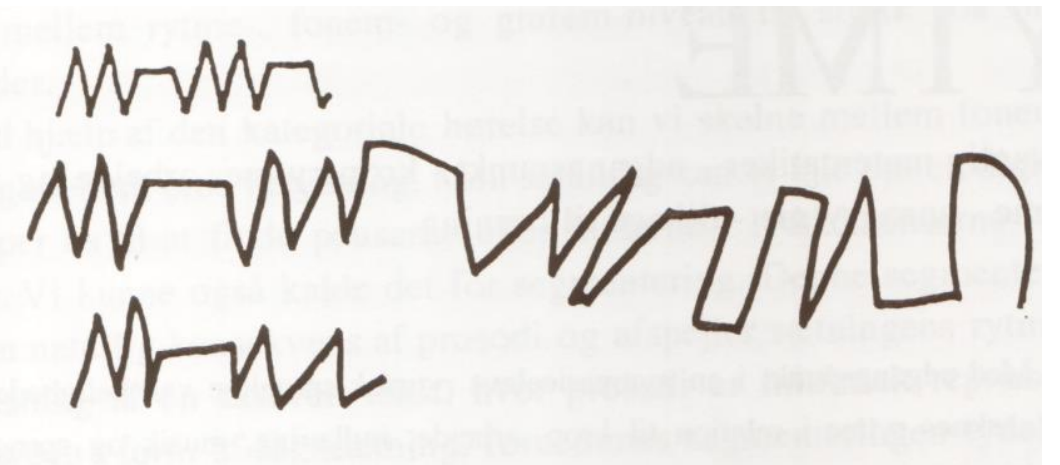

Figure 1: A) At the top: The drawing pattern that Brian must imitate, and which he is allowed to see at the same time as the movement is shown to him with an emphasis on the fluid course. B) In the middle: Brian's drawing pattern, which shows that he loses control of the movement towards the end. C) Bottom: A pattern that Brian has drawn with eyes closed. 
When he was asked to put the writing tool back on the paper and draw a 'bite' of the last and most difficult pattern with his eyes closed, he reproduced it with the correct proportions (cf. Figure 1, item C). It shows that with eyes closed in slow execution Brian masters the visuo-spatial configuration of the pattern to the full, but not the rhythmic-sequential execution of the pattern at a normally fluent pace. A spatial strength against a temporal rhythmic weakness.

2) Rhythmic knock test: Secondly, Brian could not quantify simple rhythms when he could not see the rhythm beats performed simultaneously. Especially not when it came to changes of pace. It went fairly well with monotonous rhythms, but if he had to imitate 'a knock on the door' with one accented beat and two quick and unaccented ones afterwards, Brian 'heard' it at first as 5, then as 4, and only when he was allowed to see the rhythmic knocks without them being hidden behind a sheet of cardboard, he understood that there were only three. It also caused him problems to catch up with other rhythms with changes of pace, whereas he managed monotonous rhythm beats much better.

3) Nursery rhyme test: Thirdly, Brian could not recite a simple nursery rhyme like: sip sipper nip sip sirum sip. In Brian's recitation of sentences with accumulations of consonant connections, he had difficulties with the immediate and spontaneous programming of the melodic patterns of speech. He 'stumbled' over difficult consonant connections and occasionally had to pause to avoid this 'stumble'. When Brian had tried to say 'sip sipper nip sip sirum sip' a few times without success, he looked slightly offended at John for not being able to repeat a trivial nursery rhyme and asked: "what should I use it for"? Interpretive comment: There is probably a connection between these rhythmic problems and Brian's problems acquiring the ability to immediately reproduce and automate French phrases such as: qu'est-ce qu'il y a and qu'est-ce que c'est. The latter was what his French teacher in his upper secondary school listed as some of his problems. At the same time his Danish teacher mentions related difficulties in spelling Danish inflectional endings, which is the same problem in the form of not being able to rhythmize in an articulate way.

\section{From rhymes and spelling to working memory}

The basic elements of the rhythmic-sequential theme in the form of rhythmic knocking, drawing patterns and nursery rhymes can be linked to the short-term memory which is also referred to as working memory. And Brian had difficulty both quantifying and imitating rhythms with changes of 
pace unlike monotonous rhythms without variations in stress and accent. Similarly, he had difficulty reciting meaningless rhymes, sentences with complex articulation melodies, and spellings of especially Danish inflectional endings. Here we are dealing with a phenomenon about which Miller wrote a mythological article in the middle of the 20th century: The Magical number Seven (Miller, 1956). Through experiments, he came to the conclusion that man can remember 7 plus and minus 2 when it comes to isolated individual elements such as numbers, letters, words, objects and pictures and more. Recent research has revised the result from 7 down to 5. The working memory develops from a few elements in early childhood and peaks when starting school with about 5 - 7 elements. However, we can exceed the 'magic number 7 ' by adding meaningless elements that make it easier for the brain to use its associative power by, for example, linking a series of digits to a friend's birth data or the like, it is also called mnemonics. A much more natural and often unconscious way of doing this is by rhythmizing and embedding a rhyme or a sequence of numbers in an accentuating pattern, by which one link in the chain grips and drags the next with it. It has also been called the 'Trojan horse of memory' by Nørretranders (1998), which means that much more content is smuggled into working memory than there was actually room for.

This is how we have, among many other things, learned the alphabet rhyme, the days of the week and the names of the months. You can try how difficult it is to name just one of these rhymes backwards, and as for the alphabet rhyme completely and utterly impossible. It clearly shows that the rhythm of the rhyme is more important than the individual elements. That is why Charles Ives states: "Don't pay too much attention to the sounds. If you do, you may miss the music" (Cowell \& Cowell, 1968, pp. 23-24).

Memory researcher Alan Baddeley $(1984,2003,2010)$ has for decades dealt with working memory and divided it into two main forms: 'a visual writing pad' and an 'articulation loop'. He refers to them as 'slave systems' for the working memory for short-term storage of visual and auditory stimuli, respectively. He assumes that the 'articulation loop' acts as a refresher or activation mechanism for the working memory, which appears to be important for auditory and articulatory discrimination as well as recalling syntactic patterns of sentences and syllable word structures. According to Baddeley, such a 'speech loop' in the inner voice is based on prosody and intonation. Looks like it is from here Brian is having his linguistic and written language difficulties. Dyslexics are poorer at repeating and reproducing sequences of rhymes and words with a complex articulation course. According to Baddeley, it seems that the inner voice provides an additional articulation coding during the reading process. 
Conversely, Brian performs dramatically much better when it comes to the cognitive skill of visual memory because it does not fall within the rhythmic-sequential theme. Alan Baddeley (1983) consistently refers to visual memory as visuo-spatial memory because he believes that 'tracking' via the eye movements is involved in the retention and recall of visuo-spatial stimuli. It fits in with Brian being already at pre-school level a skilled memory player with picture cards, and it fits in with dyslexics' often surprisingly strong visual memory.

\section{The consequences for reading and writing}

At this point Brian had a reasonable reading skill and managed academic texts at upper secondary school level. When he read silently, he was a slow reader. But when he read aloud, it was at a staggering speed without considering to control pauses and accents. Brian did not take periods and the delimitation of wholes of meaning into consideration, and within these he did not pay regard to commas. It can be assumed that Brian's silent reading is similarly troubled in terms of pace, progress and comprehension.

What does Brian's reading style reveal? Brian fails to create a resonance ${ }^{2}$ between the text and the reader; here resonance means reverberation, understanding. Or resonance in the sense that oscillations in one body produce similar oscillations in another body. Not only rhymes but also ordinary texts have their own rhythm. Reading is, in its origin, an oral skill. The written only comes to life when it is read aloud or the reader performs it in his own inner voice. There must be a resonance between the text and the reader. And each text has its own very precise pace. It is important to get breathing, phrasing and stressing right, so that the text is integrated into and synchronized with the reader's own rhythm and syntax. In doing so, it is absorbed, so to speak, into the reader's body and carries itself through. Brian had a hard time with this.

Similar features were seen in Brian's composition writing. There were no basic syntactic problems, but he clearly lacked the sense to pause in his units of meaning. And not only had he trivial punctuation problems, he had to an even greater extend no sense of pausing at full stop. This meant that his compositions were characterized by the absence of a common thread and a tendency to overly long sentences, which often led to far-reaching associations. Brian's spelling difficulties were particularly related to inflectional endings which are unaccented in Danish, and therefore difficult to

\footnotetext{
${ }^{2}$ Here, the concept of resonance is applied specifically to the interaction between text and reader and the harmony that arises between them; with Hartmut Rosa (2019), the concept is becoming considerably more widespread and is put into play on much more extensive sociological conditions.
} 
pick up for a student like Brian with rhythmic-sequential difficulties. It seems that Brian does not have immediate access to spontaneously rhythmize these inflectional endings instead of trying to remember them visually, auditorily or orthographically. But without the more unconscious support of rhythmization, he makes mistakes upon mistakes. He can spell foreign words much better. As an example, he mentioned the English word: interview, which he had never had problems with. Probably because it is more a matter of remembering the visuo-spatial form of the word than the rhythm of the syllable sequence.

\section{Rhythmic-sequential weakness and visuo-spatial strength}

Contrary to the rhythmic-sequential difficulties in written language skills, Brian had never had difficulties in science subjects such as mathematics, physics, and chemistry. Brian's, and other dyslexics', relative success in these subjects may be due to completely different sets of prerequisites. It seems that reading and spelling require rhythmic and audio-sequential skills, while mathematics requires bodily and visuo-spatial skills. The observations of the differences in Brian's strong and weak cognitive skills show that Brian clearly has stronger prerequisites for arithmetic and mathematics, which can be linked to the Greek mathematical geometric spaciousness. Brian feared being examined in a poem, probably because his ability to break the rhythmic code of the lines would be violently challenged; instead he hoped to be examined in image interpretation. A very good intuitive expression of rhythmic-sequential weakness and visuo-spatial strength.

In the research context, the two cognitive aspects are also referred to as 'syntagmatic' for the rhythmic-sequential and 'paradigmatic' for the visuo-spatial. By syntagmatic is meant the motor, articulatory and linguistic functions that man uses to control movements, the melodious programming of speech and the planning of syntax. The syntagmatic is linear and sequential. It has to do with sequences, rhythms and syntax. This is about organizing elements in time. By paradigmatic is meant the human skills that have to do with sensing touch on the body, the interrelationships of the body to the environment. Furthermore, to be able to perceive and place things spatially in relation to each other and finally to be able to categorize and associate linguistic concepts as a background for language comprehension. The paradigmatic has to do with seeing contexts and being able to relate perceptually and linguistically in space. Brian had written language difficulties due to the syntagmatic while the paradigmatic formed the soundboard of his strength in subjects such as physics, chemistry and mathematics. 


\section{Summary of the rhythmic-sequential theme}

Brian's gait shows something arrhythmic. It continues in obvious difficulty in tracing visual patterns in kinetic movement melodies and related difficulties in handwriting. On an articulatory level, he does not master the repetition of meaningless rhymes and sentences with complex articulation connections. And it is in itself closely linked to short-term memory in the form of the articulation loop, which is central to the ability to spell and to sound, especially Danish inflectional endings. It is heard in the reading aloud as arrhythmic accents which must affect the comprehension in silent reading.

The basic mechanisms of the rhythmic-sequential theme turn out to be bodily grounded in motor, articulatory, and linguistic difficulties in rhythmicizing sequences. The consequences seem to be most obvious for reading, spelling and writing. It seems to have implications for learning to read and to spell in the form of a limited approach to a rhythmic-sequential strategy. It is as if the rhythmicsequential 'freewheels' and does not actively participate in the reading and spelling activities.

\section{From anamnesis to catamnesis}

In his special needs pre-school Brian received help as a child to overcome his spoken language difficulties. In school, he experienced written language difficulties, which he partially overcame over time. In the upper secondary school he ran into written wording difficulties and was put under pressure in foreign languages like French. That made him consult the special needs institution for help. Here he was assessed by John Maul and he was helped to help himself. Afterwards, he moved on to university and was increasingly supported by innovations in computer technology. There was no information from his earliest childhood that could explain the problems he experienced, which is not unusual when it comes to dyslexia.

We now turn to the catamnesis, or how did it go Brian? Brian did well in the upper secondary school thanks to the science subjects. He passes his A-levels with a scraped pass grade in French and in Danish composition, but at the same time with an overall grade point average, so that he could be admitted to university. So now the former child of special needs education began a university education in science, which later leads to a leading position in the public administration. 


\section{C) Discussion: Rhythm, Dyslexia, Science, and Existential Phenomenology and}

\section{Science}

\section{Opposing views of dyslexia}

Let us conclude by comparing an existential-phenomenological approach to written language difficulties with a natural scientific approach in the form of the linguistic reading theory. It is an Anglo-Saxon inspired reading theory (see eg. Bryant \& Goswami 1990) with great impact in Scandinavia. In his Doctoral thesis from 1990 Carsten Elbro has given a coherent presentation of this linguistic reading theory of dyslexia. Here, the phoneme or language sound is made the central focal point as a causal explanation and as a means of training and teaching students with dyslexia. Here, reading difficulties are understood as difficulties with the individual sound of the language on a conscious linguistic and cognitive level. Dyslexia is defined in a linguistic context primarily as significant difficulties in learning to read and write on the basis of a slow and imprecise translation of letters and letter sequences into language sounds. In other words, according to this theory, dyslexics have difficulty in dividing coherent speech into the language sounds or phonemes that form the basis of writing. The linguistic theory can be summed up in the following sharply cut definition of reading: “decoding x comprehension = reading" (Elbro 2001, p. 28). It has over time been modified and nuanced but has unmistakable similarities with Newton's Second Law of motion (mass $\times$ acceleration $=$ resultant force) and thus a natural scientific approach to reading and dyslexia.

When, on the other hand, one learns to read, spell and write in an existentialphenomenological perspective, the visual wholes of the writing in the form of the combinations of word pictures of the individual letters are translated into fluid articulation movements and writing movements via the body, so that we end up perceiving and expressing ourselves in writing. We understand and express ourselves in spoken language; and this, of course, without having to perform conscious operations with individual elements of language sound during the process. In MerleauPonty it becomes similar to:

"The word that is read is a modulation of visual space, the motor execution is a modulation of manual space, and the whole question is how a certain physiognomy of "visual" wholes can call forth a certain style of motor responses, how each "visual" structure in the end provides its own motor essence, without our having to 
spell out the word or to spell out the movement in order to translate the word into movement" (Merleau-Ponty, 2012, p. 145).

The impeccable reading - with perfect understanding of both the listener and the reader himself - also requires pre-accents, so one must ask oneself whether the accent is the prerequisite for the understanding or the understanding is the prerequisite for the accent. It can be heard in Brian's reading which goes over "hedge and ditch", and it characterizes his silent reading which is slow and uncertain. The impaccable reading is a difficult character to capture in scientific terms. To Merleau-Ponty, it is an enigmatic phenomenon of which we will never get to the bottom.

Ricoeur (1991) has pointed out the differences between immediate understanding, explanation and interpretation, and pointed out that explanation can contribute to a greater understanding. However, it remains a sub-perspective if it is not linked to the immediate experience of the case in an overall holistic interpretation. In this article we try to offer such an interpretation, which stems from a lived understanding, which draws on partial explanations of phenomena from both human science and natural science perspectives combined in a holistic interpretation (Feilberg, 2019). It is the latter that is unique in human scientific understanding e.g. in the form of having an eye for a rhythmicsequential theme in order to comprehend such a complex phenomenon as written language difficulties, without the expectation that one can explain everything.

Existential phenomenology does not offer a scientific explanation, but we are offered an understanding that the acquisition of written language is something you identify yourself with and practise in an interweaving of movement, rhythm, speech and graphic characters.

\section{Part and whole, figure and background}

As we pointed out in the introduction, Merleau-Ponty shows the importance of including an understanding of the background, of the hidden in relation to understanding human phenomena, which cannot meaningfully be freed from the experiential dimension they arise from (Merleau-Ponty, 1968, p. 90). To understand phenomena as a whole, one must have an eye for the background from which they emerge: one must have an eye for the 'invisible', and thus for the whole we are part of, which Merleau-Ponty terms the lifeworld. The point is, in short, that the parts must not be taken out of their context, otherwise we are mistaken about them. With the concept of Bildung (Gadamer, 2004), the human scientific tradition will point out that the formation of a scientific culture depends on the building of a readiness to understand and interpret in the light of a nuanced and inclusive understanding of the complexity of human phenomena (Feilberg \& Maul, 2019). As Merleau-Ponty 
puts it: "The certitude, entirely irresistible as it may be, remains absolutely obscure; we can live it, we can neither think it nor formulate it nor set it up in theses. Every attempt at elucidation brings us back to the dilemmas" (1968, p. 11). Man is a mystery of which we must explain and understand as much as possible, without falling into the belief that we are "the creator of the world", as Arendt has put it (1946, p. 37).

Understanding for Arendt is therefore rather about coming to terms with the inscrutability of the world:

\begin{abstract}
"Understanding, as distinguished from having correct information and scientific knowledge, is a complicated process which never produces unequivocal results. It is an unending activity by which, in constant change and variation, we come to terms with and reconcile ourselves to reality, that is, try to be at home in the world" (Arendt, 1994, pp. 307-308).
\end{abstract}

As human beings, it is important to be able to wonder and to want to understand more, but without believing that one can explain everything and thus get life and existence where one wants it. In a contemporary world characterized by scientism and natural scientific ideals for documentable knowledge, it can be an extremely difficult position to occupy in practice.

\title{
Conclusion
}

We have presented an existential-phenomenological analysis of rhythm and its part in the understanding of our ability to express ourselves in written language. We have done this by combining perspectives from a number of different approaches in the form of knowledge about dyslexia, developmental psychology, neuropsychology and qualitative observations. We have combined these approaches in an overall phenomenological holistic interpretation, which constitutes more than the parts. In line with Merleau-Ponty's work, we have applied an existentialphenomenological attitude, in the sense of presenting different perspectives as a contribution to an overall understanding, but doing so in the light of an explicit ontology of the human being, which takes the experiencing body-subject as the basis and our starting point.

In other words, when we apply a perspective on a phenomenon, it can only be a subperspective that merely highlights one aspect of a phenomenon, i.e. just contributions or "moments 
of my total being" (Merleau-Ponty, 2012, p. 482). We live more than we can conceptualize and describe.

Thus, we have arrived at the main message of the article: that human science knowledge contributes crucial aspects of the conceptuality and the understandings that all other sciences take for granted. Countering reductionism, showing that scientific achievements can be combined and interpreted in the continuation of human science understanding, was one of the characteristics of Merleau-Ponty's existential phenomenology, and a tradition to which we wish to continue to contribute.

\section{References}

Arendt, H. (1994). Essays in Understanding, 1930 - 1954, ed. Jerome Kohn, N. Y.: Hartcourt Brace \& Co.

Baddeley, A.D., V Lewis, \& G. Vallar (1984). Exploring the Articulatory Loop, Quarterly Journal of Experimental Psychology, 36A, 233-252.

Baddeley, A. (2003) Working Memory: Looking back and looking forward, Nature Reviews Neuroscience 4, $829-839$.

Baddeley, A. (2010). Working Memory, Current Biology, Volume 20, Issue 4, 136 - 140.

Barbaras, R. (2005). Phenomenology of life. In: T. Carman \& M. B. N. Hansen (eds.), The Cambridge Companion to Merleau-Ponty, (pp. 206-230). Cambridge: Cambridge University Press.

Bastian, S. (1987). Ind i musikken, en bog om musik og bevidsthed, [Into the Music, a Book about Music and Consciousness]. Copenhagen: Gyldendal.

Bjørkvold. J.R. (1992). The Muse Within, Creativity and comunication in Song and Play from Childhood through Maturity, New York: Harper Collins Publishers.

Bryant, P. \& U. Goswami. (1990). Phonological Awareness and Learning to Read,

In: Beech \& Colley (Eds.): Cognitive Approaches to Reading, New York: Wiley.

Christensen, A.L. (1975). Luria's Neuropsychological Investigation, Copenhagen: Munksgaard.

Christensen, A.L. \& Caetano, C. (1999). Luria's Neuropsychological Evaluation in the Nordic Countries. Neuropsychol Rev 9, 71-78. https://doi.org/10.1023/A:1025655707095

Compton, J. (1997). Existential phenomenology. In: L. Embree (ed.), Encyclopedia of Phenomenology, (pp. 205-209). Dordrecht: Kluwer.

Cowell, H. \& Cowell, S. (1968). Charles Ives and his Music, New York: Oxford University Press. 
Elbro, C. (1990). Differences in Dyslexia. A Study of Reading Strategies and Deficits in a Linguistic Perspective. Copenhagen: Munksgaard International Publishers, Ltd.

Elbro, C. (2001). Laesning og laseundervisning [Reading and Reading Instruction], Copenhagen: Gyldendal.

Feilberg, C. (2012). Eksistentiel fænomenologi - betegnelsen, stilen og begrebet. In: K. D. Keller (red.), Den menneskelige eksistens. Introduktion til den eksistentielle fanomenologi, (pp. 4575). Aalborg Universitetsforlag.

Feilberg, C. (2014). Dannelsen af en psykologisk og videnskabelig habitus hos psykologistuderende. PhD Thesis. Academic Books.

Feilberg, C. (2019). Metodologisk refleksion: ved kvalitative iagttagelser og undersøgelser. I C. Feilberg, \& J. Maul (red.), Kvalitative iagttagelser: at forstå, unders $\emptyset$ ge og udrede mennesker på et eksistentiel-fanomenologisk grundlag (pp. 65-105). Aalborg Universitetsforlag. Skriftserie om eksistentiel fænomenologi

Feilberg, C. \& J. Maul (2019). Kvalitative iagttagelser At forstå, unders $\phi g$ ge og udrede mennesker på et eksistentiel-fanomenologisk grundlag, Aalborg Universitetsforlag.

Feilberg, C., Norlyk, A., \& Keller, K. D. (2018). Studying the Intentionality of Human Being: Through the Elementary Meaning of Lived Experience. Journal of Phenomenological Psychology, 49(2), 214-246. DOI: https://doi.org/10.1163/15691624-12341347

Gadamer, H. G. (2004). Truth and Method (2nd Ed). Continuum.

Grant, S. (2010). Some Suggestions for a Phenomenology of Rhythm. In E. D. L. Fuente \& S. Murphy (eds.), Philosophical and cultural theories of music (pp. 151-173), Brill.

Grønbech, V. (1943). Sprogets Musik, (The Music of Language) Copenhagen: H.C. Branners Forlag. Habermas, J. (1978). Knowledge and human interests. Appendix: Knowledge and human interests: A general perspective (2nd ed) (pp. 301-350). Trans. Shapiro. Beacon Press: Boston.

Hansen, E. og J. Lund (1983). Sat tryk på dansk, syntaktisk tryk på dansk [Stressing in Danish, syntactic stressing in Danish], Copenhagen, Lærerforeningens materialeudvalg.

Lefebvre, H. (2013). Rhythmanalysis: Space, time and Everyday Life, New York: Bloomsbery Academic.

Løgstrup, K.E. (1976). Vidde og Pragnans - Sprogfilosofiske Betragtninger [Breadth and Concision] Copenhagen: Gyldendal. 
Maul, J. (1995). Studier $i$ et rytmisk sekventielt tema $i$ dysleksi, (Studies in a rhythmic sequential theme in dyslexia) Copenhagen: ph.d. thesis, The Royal Danish School of Educational Studies http://livsverden.dk/pub/Maul.J.1995.PHD.pdf

Maul, J. (2000). Temaer i laese- og stavevanskeligheder hos børn og unge, (Themes in reading and spelling difficulties in children and adolescents), Herning: Specialpædagogisk Forlag.

Maul, J. (2000a). Screening af laesning og forudsatninger for laesning og stavning, (Screening of reading and prerequisites for reading and spelling) Herning: Specialpædagogisk Forlag.

Merleau-Ponty, M. (1967). The Structure of Behavior. Boston: Beacon press.

Merleau-Ponty, M. (1968). The Visible and the Invisible. Evanston, IL: North-western University Press.

Merleau-Ponty, M. (2012). Phenomenology of Perception. (transl. by D. Landes). London: Routledge.

Miller, G. A. (1956). The magical number seven, plus or minus two: some limits on our capacity for processing information. Psychological Review, 63(2), 81-97. https://doi.org/10.1037/h0043158

Nørretranders, T. (1998). The User illusion: Cutting Consciousness down to Size, UK: Allen Lane Penguin Press.

Olesen, S. G. (1993). Filosofien i Frankrig eller Frankrig i Filosofien [Philosophy in France or France in Philosophy]: Slagmarks Skyttegravsserie.

Ricoeur, P. (1991). From Text to Action - Essays in Hermeneutics, II, Chap. 6: Explanation and Understanding (pp. 125-143). Evanston IL: Northwestern University Press.

Rosa, H. (2019) Ressonnance. A Sociology of our Relationship to the World, Cambridge: Polity Press.

Stenzel, J. (1934). Philosophie der Sprache (Philosophy of language), R. Oldenburger Verlag, München.

Trevarthen, C. (1987). Sharing Makes Sense. Intersubjektivity and the Making of an Infant's Meaning In: R. Steele (Ed.): Language Topics Essays in Honour of Michael Halliday, Amsterdam, Philadelphia.

Trevarthen, C. (1988). Infant's Trying to Talk, How a Child Invites Communication from the Human World, In: R. Söderbergh (Ed.), Children's Creative Communication, Lund.

Trevarthen, C. (1999). Musicality and the Intrinsic Motive Pulse: Evidence from human psychobiology and infant communication. Musicae Scientiae, 3(1_suppl), 155-215. https://doi.org/10.1177/10298649000030S109 
Trevarthen, C. \& Malloch, S. (2010). Communicative Musicality: Exploring the Basis of Human Companionship, Oxford University Press.

Wiskus, J. (2013). The Rhythm of Thought Art, Literature, and Music after Merleau-Ponty. Chicago: University of Chicago Press.

\begin{abstract}
About the authors
Casper Feilberg, $\mathrm{PhD}$, is an Associate Professor in Educational Psychology at the Department of Communication and Psychology, Aalborg University, Denmark. His topics of research are Pedagogy, Bildung, Professional Development in Higher Education - especially the Profession of psychology, Problem oriented Project work. The main philosophical and theoretical inspirations are Existential phenomenology (Merleau-Ponty, Heidegger, Gadamer, Ricoeur), psychoanalysis (Bion) and critical theory (Habermas, Negt). I make use of Qualitative methodology and several research methods.
\end{abstract}

John Maul, PhD, Speech therapist and former Ass. Professor in Special Education at the Danish University of Education, later University College of Northern Jutland. John Maul is originally speech therapist from the Royal Danish School of Educational Studies and PhD with a dissertation on a qualitatively interpretive view of dyslexia; based on a working odyssey through cerebral palsy, aphasia, dysphasia and dyslexia with consequences for understanding the importance of movement, rhythm and body. Homepage editor of livsverden.dk, homepage of The Danish Society for Existential Phenomenology. 